\title{
PUBLISHERCORRECTION
}

\section{Correction to: A transcendental Brauer-Manin obstruction to weak approximation on a Calabi-Yau threefold}

\author{
Sachi Hashimoto ${ }^{1 *} \mathbb{D}$, Katrina Honigs ${ }^{2}$, Alicia Lamarche ${ }^{3}$ and Isabel Vogt ${ }^{4}$
}

${ }^{*}$ Correspondence:

sachivhashimoto@gmail.com

${ }^{1}$ Department of Mathematics and Statistics, Boston University, Boston, MA 02215, USA

Full list of author information is available at the end of the article

\section{Correction to: Res. number theory https://doi.org/10.1007/s40993-021-00307-4}

We would like to inform you that Nicolas Addington was inadvertently identified as a coauthor of the above article. His contribution to this article refers strictly to its appendix entitled The Brauer group of Hosono and Takagi's threefold.

We apologize for any misunderstanding this has caused.

\section{Author details}

'Department of Mathematics and Statistics, Boston University, Boston, MA 02215, USA, ${ }^{2}$ Department of Mathematics, Simon Fraser University, Burnaby, BC V5A 156, Canada, ${ }^{3}$ Department of Mathematics, University of Utah, Salt Lake City, UT 84112, USA, ${ }^{4}$ Department of Mathematics, Brown University, 151 Thayer Street, Providence, RI 02912, USA.

The original article can be found online at https://doi.org/10.1007/s40993-021-00307-4.

Published online: 7 March 2022

\section{Publisher's Note}

Springer Nature remains neutral with regard to jurisdictional claims in published maps and institutional affiliations. 